\title{
AgNOR counts in conjunctival malignant melanoma lack prognostic value
}

\author{
A D A Paridaens, S Seregard, D Minassian, J L Hungerford, A C E McCartney
}

\begin{abstract}
Using a silver staining technique, argyrophilic nucleolar organiser region-associated proteins (AgNORs) have been studied in routinely processed paraffin sections of 46 invasive malignant melanomas (MM) of the conjunctiva. The aim of this retrospective study was to assess the value of the AgNOR method as a prognostic indicator for this neoplasm. The 46 cases were divided into two groups: (A) 14 cases of MM that metastasised and caused death of the patient within 5 years of (histological) diagnosis, and (B) 32 cases of $M M$ that did not metastasise and in which patients survived beyond 5 years. The mean of the AgNOR counts per nucleus was 7.03 (95\% CI: 5.81-8.24) in group $A$, and 7.15 (95\% CI: 6.537.77) in group B. A comparison using a multifactor analysis of variance (ANOVA) model, which corrected for possible confounding effect of tumour thickness, site, and cell type showed no significant difference in AgNOR counts between groups $A$ and $B(p=0.8)$. Analysis by the Cox proportional hazards regression model showed that survival was not influenced significantly by the mean AgNOR number (hazard ratio: 0.92). Whereas the AgNOR technique may be used to distinguish benign from malignant melanocytic lesions of the conjunctiva, we conclude it has no value in predicting the outcome for patients with conjunctival MM.
\end{abstract}

(Br f Ophthalmol 1992; 76: 621-623)

Department of Pathology, Institute of Ophthalmology A D A Paridaens ${ }^{\star}$ $S$ Seregard $t$

A C E McCartney

Department of Preventive Ophthalmology, Institute of Ophthalmology

D Minassian

Moorfields Eye Hospital and St Bartholomew's Hospital, Oncology Clinics

J L Hungerford

^Current address: F C Donders Institute of Ophthalmology, Heidelberglaan 100, 3584

CX Utrecht, The

Netherlands.

†Current address: St Erik's Eye Hospital, Fleminggatan 22, S-112 82 Stockholm, Sweden.

Correspondence to: Dr A C E McCartney, Department of

Pathology, Institute of Ophthalmology, 17-25 Cayton Street, London ECIV 9AT.

Accepted for publication 21 May 1992
Nucleolar organiser regions (NORs) are loops of ribosomal DNA which transcribe to ribosomal RNA. NORs are associated with the five acrocentric chromosomes $(13,14,15,21$, and 22) and can be visualised in the nuclei of cells as black/brown dots by virtue of the argyrophilia (Ag) of their associated proteins, including RNA polymerase-1, B-23, and C-23. ${ }^{1}$

Silver staining of the AgNOR proteins has been used as a technique to study the nucleolar morphology and the variations of nucleolar activity, ${ }^{2}$ and the number and size of AgNORs are thought to reflect rDNA transcriptional activity. ${ }^{3}$ Since the introduction of the one step, simplified AgNOR technique, ${ }^{+}$which can be applied to routinely processed paraffin wax embedded histological specimens, several studies $^{5-11}$ have been conducted to evaluate the possible association between AgNORs and malignancy of melanocytic lesions. The AgNOR technique has been applied to melanocytic tumours of the skin, ${ }^{567}$ and those of the eye, including the iris, ${ }^{8}$ choroid,${ }^{89} 10$ and conjunctiva. ${ }^{11}$

These studies indicated that enumeration of AgNORs is useful in discriminating benign from malignant lesions, though some overlap in AgNOR counts was observed. There have been only few reports ${ }^{912}$ that studied the prognostic value of the silver staining method in melanocytic lesions. The aim of this study was to investigate the prognostic significance of AgNOR counts in malignant melanoma of the conjunctiva.

\section{Materials and methods}

\section{SELECTION OF CASES}

Clinical information on patients with conjunctival malignant melanoma who were treated in the ocular oncology unit of Moorfields Eye Hospital and St Bartholomew's Hospital was retrieved from a database (Paradox 3), maintained at the Institute of Ophthalmology. Slides containing the histological sections of the tissue biopsy specimens of these patients were reviewed to verify the diagnosis of invasive malignant melanoma (MM) of the conjunctiva.

We selected 60 cases that had been followed up for 5 or more years or to the date of death owing to conjunctival melanoma. Patients who died within 5 years from any cause other than metastatic melanoma were not included. For each case the location, the maximum thickness, and the cell type of the surgically (completely) excised original tumour were recorded. After the silver staining of the 60 histological sections, 14 cases were discarded because of difficulties in visualisation of AgNORs, mainly caused by heavy melanin deposits obscuring the view or poor staining.

The 46 remaining cases were divided into two groups for comparison of AgNOR counts: (A) 14 cases of $M M$ in which death from metastasis occurred within 5 years of diagnosis, and (B) 32 cases of MM that did not metastasise, with patients' survival beyond 5 years.

SILVER STAINING TECHNIQUE

Sections were cut at $3 \mu \mathrm{m}$ thickness and were dewaxed in xylene and hydrated through graded ethanols. The sections were processed to demonstrate AgNORs at room temperature for 30 minutes. ${ }^{13}$ The reaction mixture comprised $2 \%$ gelatin in $1 \%$ aqueous formic acid. This was mixed in a proportion of $1: 2$ volumes with $50 \%$ aqueous silver nitrate under dark room conditions. After staining the sections were exposed to xylene and mounted in synthetic medium.

\section{COUNTING PROCEDURE}

All sections were examined by two observers, using an oil immersion lens $(\times 100)$. Both observers recorded the total number of AgNORs 


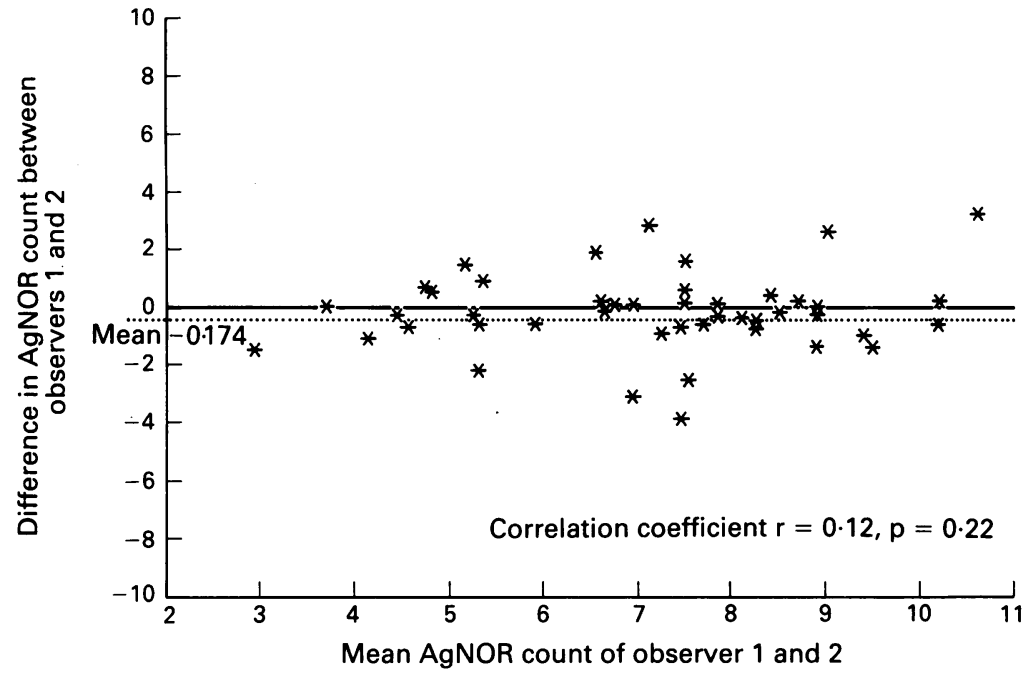

Figure 1 Difference between observer 1 and 2 in AgNOR count of the same specimen $(C 1-C 2)$, plotted against the mean of the two counts $(C 1+C 2) / 2$. The differences are mostly trivial, with a small mean of $-0 \cdot 174$, and appear to be independent of the mean count, showing no systematic pattern of change in magnitude with higher values of the mean count. The correlation of the differences with the mean values is small and not significant, so that an assumption of independence is not contradicted by the data.

per nucleus, including both nucleolar and extranucleolar NORs, for 30 nuclei, as suggested by Orrell et $a l,{ }^{7}$ and calculated a mean value. Subsequently, a mean value of both observations (total of 60 nuclei) was calculated for every section.

\section{STATISTICAL ANALYSIS}

The mean AgNOR counts in the two groups were compared using a multifactor analysis of variance (ANOVA) model. This allowed adjustments to be made for possible confounding effect of three other variables: tumour thickness, cell type, and site. Further analysis, to evaluate the relationship between AgNOR counts and survival, was carried out using the Cox proportional hazards models.

The agreement between the two observers in evaluating the mean count of AgNORs was assessed by analysis of the difference in the paired observations. The mean difference was

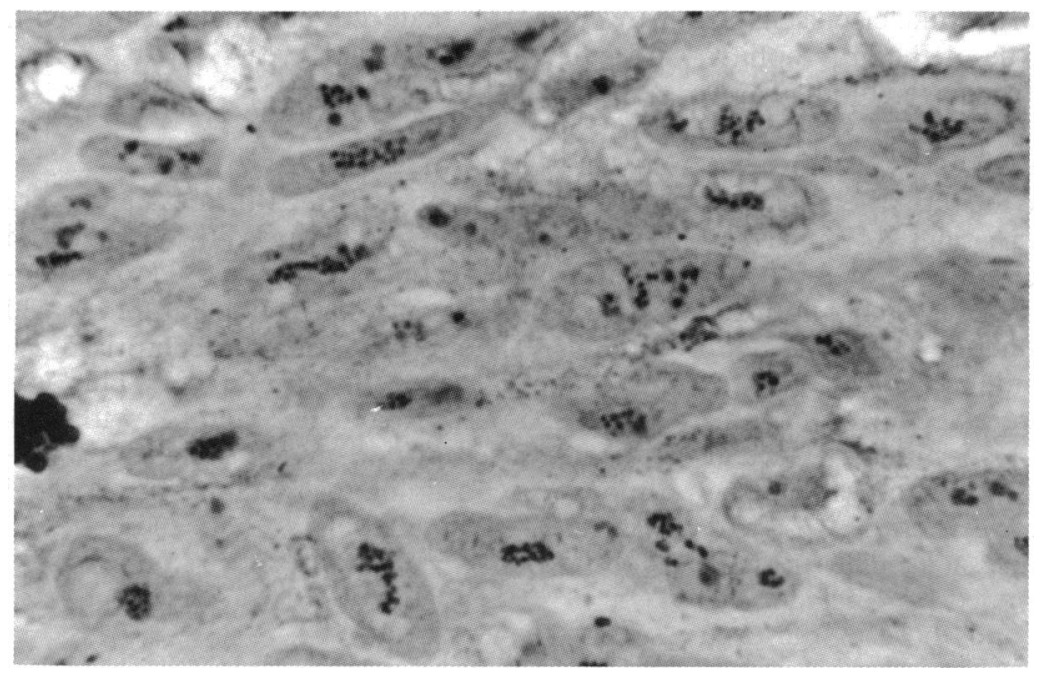

Figure 2 Conjunctival malignant melanoma: high number of AgNORs, visible as black dots in the nuclei of the tumour cells (silver stain, $\times 280)$. computed to give a measure of bias, and the standard deviation of the differences provided a measure of error owing to - for example, poor repeatability. The hypothesis of zero bias was tested by a paired $t$ test. ${ }^{14} \mathrm{~A}$ plot of the differences between the two observers against the mean of the two observers (Fig 1) was constructed to demonstrate the magnitude of disagreement in the AgNOR counts by the two observers, and to show dependence or otherwise of the degree of agreement upon the magnitude of the counts. The presence or absence of such dependence was formally tested though correlation analysis. A similar analysis was done for nine pairs of repeat counts by one of the observers.

\section{Results}

In the selection of specimens AgNORs were visible as black dots of varying sizes in the nuclei (Fig 2). In the majority of cases the dots were clustered within an argyrophilic nucleolus, but in some cases AgNORs were dispersed throughout the nucleus. In the $3 \mu \mathrm{m}$ sections there appeared to be little overlap of cells, which might give rise to artificially high counts in thicker sections.

Data from the AgNOR counting are shown in Table 1. The mean AgNOR counts were 7.03 (range $2.95-10.6$ ) in group $A$, and $7 \cdot 15$ (range $3 \cdot 7-10 \cdot 2)$ in group $B$. The difference was not significant $(p=0.8)$, and remained so after adjustment for possible confounding effect of tumour thickness, cell type, and site (Table 1). No adjustment was necessary for the influence of multifocality of melanoma at diagnosis as a simular incidence of multifocal lesions was seen in both groups.

Analysis by the Cox proportional hazards regression model incorporating the three possible confounders showed that survival was not influenced significantly by the AgNOR counts. The hazard ratio for the mean AgNOR count term was close to unity $(0.92)$ with a $95 \%$ confidence interval of $0.72-1 \cdot 16 \quad(p=0.46)$. There were no significant higher order interactions, indicating no effective modification by any of the other three factors - that is, the lack of association between AgNOR count and survival was consistent in subgroups with different tumour thickness, cell type, or tumour site.

There was good agreement between the two observers in counting AgNORs. The mean of the differences between the paired counts was $-0 \cdot 174$ (standard error $=0 \cdot 2, p=0 \cdot 4$ ), indicating no significant bias. The standard deviation of the differences was $1 \cdot 36$. The differences (degree of disagreement) did not seem to depend upon the magnitude of the counts (Fig 1). The assumption of independence was not contradicted by the data (correlation coefficient $\mathrm{r}=0 \cdot 12, \mathrm{p}=0 \cdot 22$ ). The intraobserver agreement, in repeat counts of a small subsample of nine specimens, also showed close agreement (mean of differences $=$ 0.3 , standard deviation $=0.52$ )

\section{Discussion}

Malignant melanoma of the conjunctiva is rare but is among the most serious of ocular 
Table 1 Analysis of variance comparing the mean AgNOR count in the two groups $A$ and $B$ (those who died within 5 years of follow up and the survivors respectively)

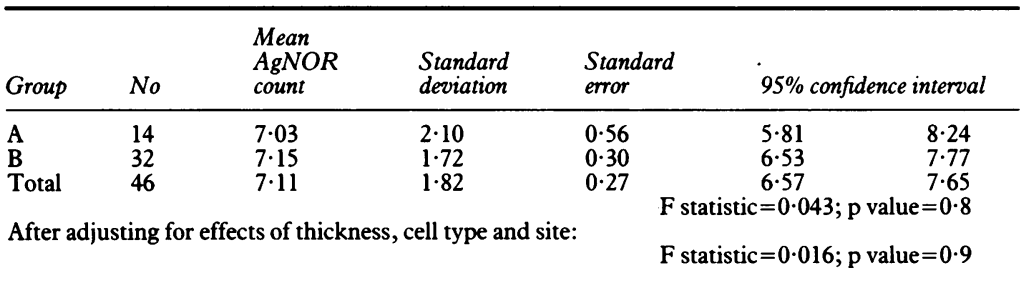

Cochran's $C$ and Bartlett-Box $F$ tests: $p$ values are 0.36 and 0.39 , indicating no violation of the 'homogeneity of variance' assumption

malignancies. This tumour may arise de novo, from a pre-existing naevus, or from an area of primary acquired melanosis (PAM). The latter precursor is acquired at adult age and is often multifocal, thus putting the patient at risk of multicentric melanoma. Silvers et $a l^{15}$ have demonstrated that thickness of the patient's thickest conjunctival melanoma is a good indicator of poor prognosis, a finding which was confirmed by Folberg et al. ${ }^{16}$ Other factors that may be prognostic indicators include tumour location and cell type. Several authors have found a worsened outcome in multicentric melanoma and in melanomas involving the fornices, the palpebral conjunctiva, and the caruncle, ${ }^{17} 1819$ but there has been no large study which has demonstrated a higher death rate from melanomas arising from PAM with atypia. ${ }^{16} 17$

The number of AgNORs has been reported to be of prognostic value in breast carcinomas. ${ }^{20}$ In a study of uveal melanomas, Marcus et $a l^{10}$ found a correlation between AgNORs and the 5 and 10-year estimated survival. They concluded that AgNORs may therefore be of value in predicting prognosis for uveal melanomas, but their data remain to be correlated to survival statistics. In a previous study from this group ${ }^{9}$ we have not found this to be true and this nonagreement is echoed in cutaneous $M M$ where Howat $e t a l^{12}$ also found no correlation between AgNOR counts and metastasis. In the latter study it was argued that while AgNORs may reflect cell proliferation rate the development of metastases may be determined by a variety of other factors.

Our study showed no significant difference in mean AgNOR counts between the two comparison groups $\mathrm{A}$ and $\mathrm{B}$, which represent cases with good and poor 5-year outcomes respectively. Had there been a true difference of at least $2 \cdot 0$ (for example, population mean of $A=9$ and of $B=7)$, the study would have had a $95 \%$ probability of detecting it as significant (critical $p$ value being 0.05 ). This suggests that the clinical outcome depends on factors other than AgNOR number.

The mean of the mean AgNOR counts in this study was $7 \cdot 1$, which is markedly higher than the mean count of 5.7 that was recently observed in another study of 14 conjunctival melanomas"; however, interestingly, they reported that none of their cases had a lower AgNOR count than $4 \cdot 0$, whereas in two of our cases we counted $3 \cdot 7$ and 3.0 AgNORs respectively.

Despite subjectivity in resolving single AgNORs within nucleolar argyrophilic clumps and the relatively small sample sizes, there was good inter and intraobserver agreement. Some of the apparent disagreement may be attributed to sampling errors. Whereas the AgNOR technique may be useful as a tool for the differential diagnosis of conjunctival or other ocular melanocytic lesions, ${ }^{8-11}$ we conclude that assessment of AgNOR number is of no prognostic significance for MM of the conjunctiva.

We thank Mr R A Alexander, $M$ Phil for his kind help with the AgNOR staining. This study was supported by a grant to $D$ A D A Paridaens from Stichting Dr Fischer, Utrecht, the Netherlands.

1 Hernandez-Verdun D. The nucleolar organizer regions. Bio Cell 1983; 49: 191-202.

2 Howell WM. Selective staining of nucleolus organizer region (NORs). In: Busch H, Rothblum L, eds. The cell nucleus, Vol XI, New York, London: Academic Press, 1982: 89-142. 3 (Editorial) NORs - a new method for the pathologist Lance 1987; i: $1413-4$

4 Crocker J, Nar P. Nucleolar organizer regions in lymphomas. F Pathol 1987; 151: 111-8.

5 Crocker J, Skilbeck N. Nucleolar organiser region associated proteins in cutaneous melanotic lesions: a quantitative study. F Clin Pathol 1987; 40: 885-9.

6 Leong A S-Y, Gilham P. Silver staining of nucleolar organize regions in malignant melanoma and melanotic nevi. Hum Pathol 1989; 20: 257-62.

7 Orrell JM, Evans AT, Grant A. A critical evaluation of AgNOR counting in benign naevi and malignant melanoma. AgNOR counting in benign

8 Deuble K, McCartney A. Nucleolar organising regions in iris melanocytic tumours: an accurate predictor? Eye 1990; 4 melanocy

9 Williams RA, Rode J, Chariton IG, Johns L, McCartney A. DNA content and nucleolar organising regions in ocular DNA content and nucleolar organisi
melanoma. $\mathcal{F}$ Pathol 1988; 156: $342 \mathrm{~A}$.

10 Marcus DM, Minkovitz JB, Wardwell SD, Albert DM. The value of nucleolar organizer regions in uveal melanoma. value of nucleolar organizer regions

11 Saornil MA, Marcus DM, Albert DM, Apolone G, Torri V. The role of nucleolar organizer regions (NORs) in deter mining malignancy in pigmented conjunctival lesions ARVO 1991; 32: 1198 A

12 Howat AJ, Giri DD, Wright AL, Underwood JCE. Silverstained nucleoli and nucleolar organizer region counts are of no prognostic value in thick cutaneous malignant melanoma. $\mathcal{F}$ Pathol 1988; 156: 227-32.

13 Ploton D, Menager M, Jeannesson P, Himber G, Pigeon F Adnet JJ. Improvement in the staining and in the visualization of the argyrophilic proteins of the nucleolar organize region at the optic level. Histochem $\mathcal{F} 1986 ; 18: 5-14$

14 Altman DG, Bland JM. Measurement in medicine: the analysis of method comparison studies. Statistician 1983; 32 307-17.

15 Silvers D, Jakobiec FA, Freeman T, et al. Melanoma of the conjunctiva: a clinicopathologic study. In: Jakobiec FA, ed. Ocular and adnexal tumors. Birmingham, Alabama: Aesculapius, 1978, pp 583-99.

16 Folberg R, McLean IW, Zimmerman LE. Malignant melanoma of the conjunctiva. Hum Pathol 1985; 16: 136-43.

17 Jay B. Naevi and melanomata of the conjunctiva. $B r f$ Ophthalmol 1965; 49: 169-204.

18 Crawford JB. Conjunctival melanomas: prognostic factors. A review and an analysis of a series. Trans Am Ophthalmol Soc review and an analysic

19 Jeffrey IJM, Lucas DR, McEwan C, Lee WR. Malignant melanoma of the conjunctiva. Histopathology 1986; 10: 36378.

20 Giri DD, Nottingham JF, Lawry J, Dundas SAC, Underwood JCE. Limitations of the Ag-NOR technique in distinguishing between benign and malignant epithelial lesions of the breast. F Pathol 1988; 154: 44 A.

21 Sivridis E, Sims B. Nucleolar organiser regions: new prognostic variable in breast carcinomas. F Clin Pathol 1990; 43: 390-2 